\section{Vibrotactile thresholds measured at the finger*}

\author{
RONALD T. VERRILLO' \\ Laboratory of Sensory Communication, Syracuse University, Syracuse, New York 13210
}

Absolute vibrotactile thresholds were determined over the distal pad of the middle finger and thenar eminence of the right hands of five Ss. Measurements were made using eight frequencies between 25 and $700 \mathrm{~Hz}$ and seven contactor sizes between .0008 and $1.3 \mathrm{~cm}^{2}$. When plotted as a function of frequency, the threshold curve measured at the fingerpad with a $.005-\mathrm{cm}^{2}$ contactor is $U$ shaped, with a maximum sensitivity in the region of $250 \mathrm{~Hz}$. When plotted as a function of contactor size, the threshold decreases at a rate of $3 \mathrm{~dB}$ per doubling of the area.

The duplex theory of cutaneous innervation (Verrillo, 1968) is in part based on the finding that over the thenar eminence and volar forearm absolute vibrotactile thresholds are constant over changes in frequency when very small contactors are used. For large contactors the typical threshold function is $U$ shaped with a slope of approximately $12 \mathrm{~dB}$ per doubling of frequency and reaching a maximum of sensitivity in the region of $250 \mathrm{~Hz}$. It was also shown that spatial summation was absent at frequencics below $40 \mathrm{~Hz}$. At higher frequencies the threshold decreased with contactor size at a rate of $3 \mathrm{~dB}$ per doubling of the contactor area. Hill (1967), however, reported for one $S$ that a small contactor $\left(.002 \mathrm{~cm}^{2}\right)$ over the fingertip produced an integrating effect across frequencies. This is a reasonable expectation since the Pacinian corpuscle, which is the end organ most likely responsible for the integration (Verrillo, 1966b; Merzenich \& Harrington, 1969), has a very high density in the finger (Winkelmann, 1960). It may be impossible to avoid stimulating one of these receptors regardless of the contactor size. The experiments reported here were performed in order to explore in greater detail the vibrotactile response at the fingertip.

\section{APPARATUS AND METHOD}

The apparatus and experimental conditions are described in detail elsewhere (Verrillo, 1963, 1968). Threshold determinations were made on five Ss over the distal pad of the middle finger and thenar eminence of the right hand at eight frequencies, ranging from 25 to $700 \mathrm{~Hz}$. A contactor area of $.005 \mathrm{~cm}^{2}$ was used with a gap of $1.0 \mathrm{~mm}$ between the contactor and

*This study was supported by Grant GB-8412 from the National Science Folndation and Grant NIN D B-NB-03950-08 from the National Institutes of Health, U.S. Department of Health, Education and Welfare.

tAddress: Laboratory of Sensory Communication, Syracuse University, 821 University Avenue, Syracuse, New York 13210 the rigid surround. The sinusoidal bursts were pulsed at a rate of $1 \mathrm{sec}$ on and $1 \mathrm{sec}$ off. Ss were located within a soundproof booth to isolate them from unwanted vibrations. Narrow-band noise, delivered through insert earphones, prevented them from hearing any tones produced by the vibrator.

In order to study the effect of spatial summation on the finger, individual thresholds were measured for seven contactor sizes $(.0008, .005, .02, .08, .32$, .72 , and $1.3 \mathrm{~cm}^{2}$ ) at frequencies of 25 and $250 \mathrm{~Hz}$. According to the hypothesis that the mechanoreceptor system containing Pacinian corpuscles summates energy over spatial increments at higher frequencies but is unresponsive to these increments at low frequencies, we should expect a slope of approximately $-3 \mathrm{~dB}$ per doubling of area at $250 \mathrm{~Hz}$ and a constant threshold at $25 \mathrm{~Hz}$.

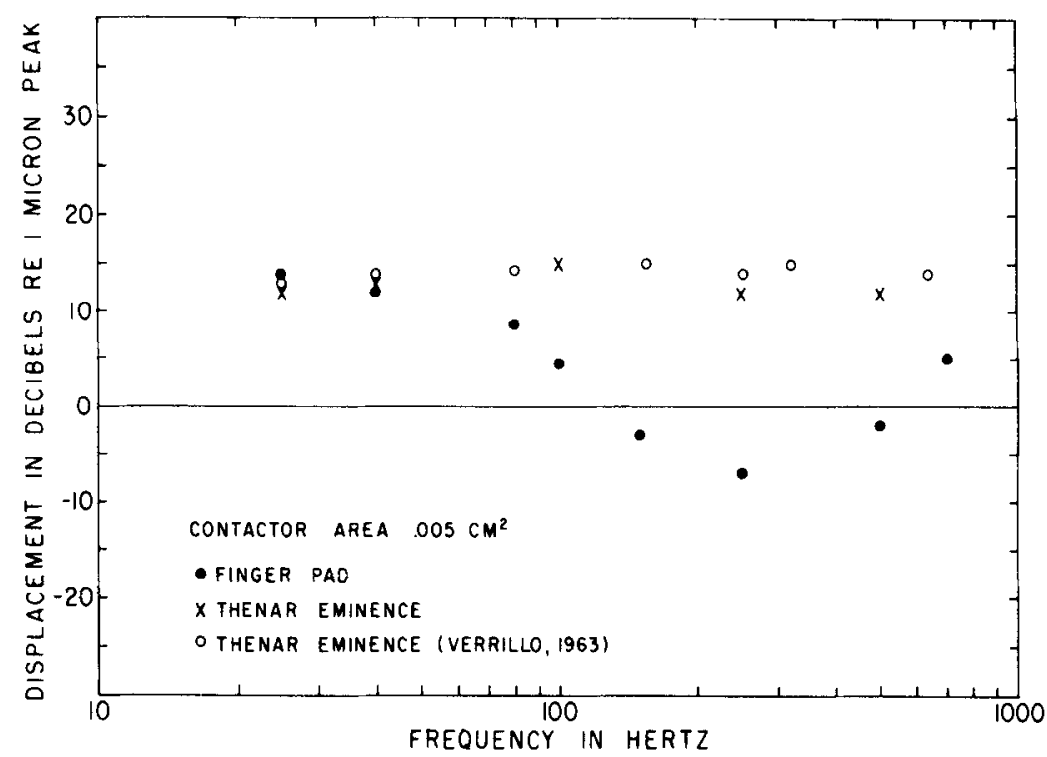

Fig. 1. Absolute thresholds for fibration plotted as a function of stimulus frequency. Results obtained fromthe middle fingerpad $(\bullet)$ are compared with thresholds determined over the thenar eminence (X). The contactor size was $.005 \mathrm{~cm}^{2}$. Results of a previous experiment $(O)$ using the same contactor size over the thenar eminence are shown for comparison. 


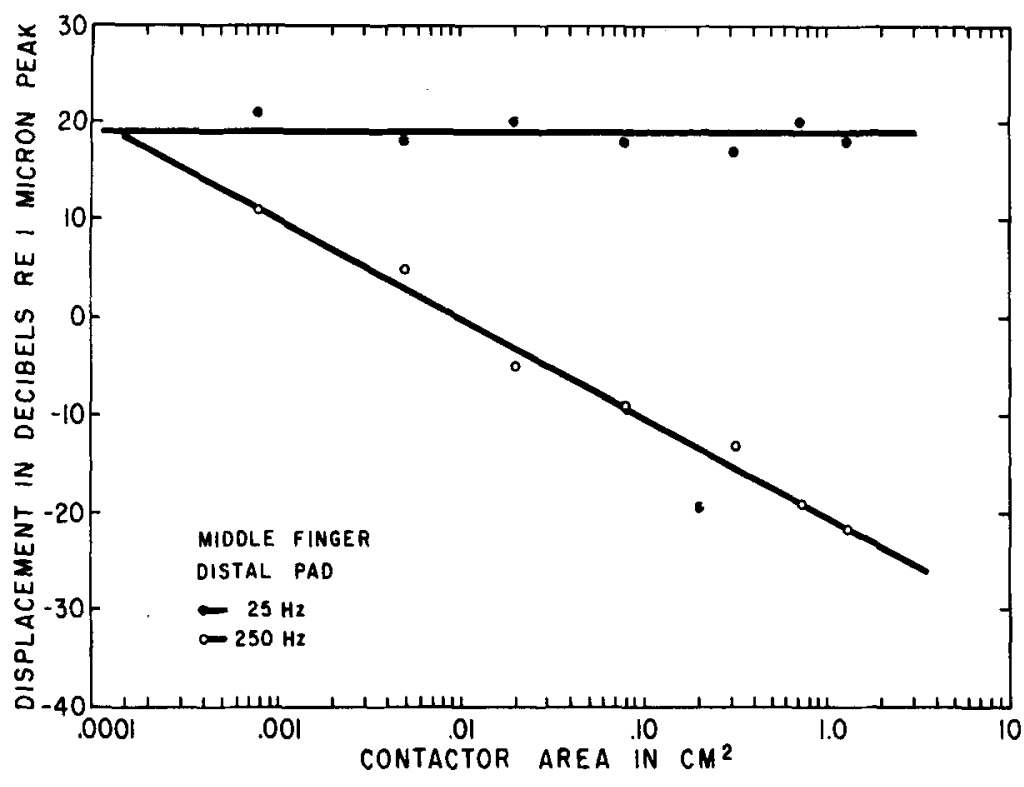

Fig. 2. Absolute thresholds for vibration plotted as a function of contactor size. At $250 \mathrm{~Hz}(O)$ the threshold decreases at a rate of $3 \mathrm{~dB}$ per doubling of area. At $25 \mathrm{~Hz}(\bullet)$ the contactor area has no effect upon threshold levels.

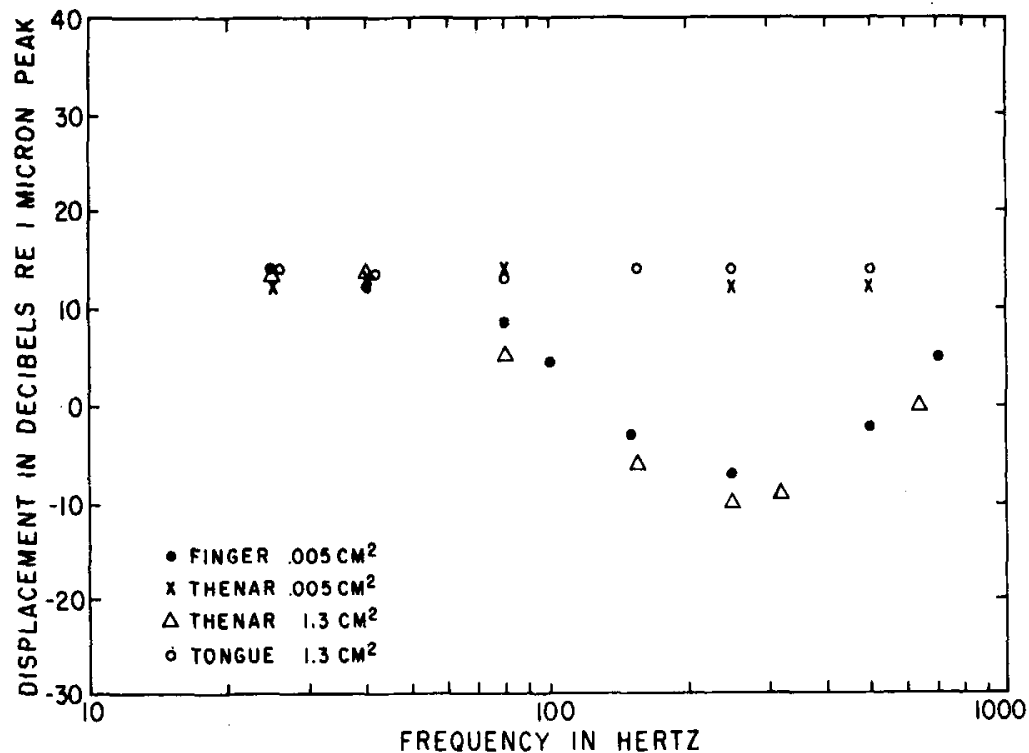

Fig. 3. Comparison of absolute vibrotactile thresholds obtained at different body sites plotted as a function of stimulus frequency. Responses at the fingerpad ( $\bullet$ ) using a contactor area of $.005 \mathrm{~cm}^{2}$ are close to those obtained over the thenar eminence $(\Delta)$ using a much larger $\left(1.3 \mathrm{~cm}^{2}\right)$ contactor. The threshold curves of the thenar eminence measured with a $.005-\mathrm{cm}^{2}$ contactor $(X)$ resemble those obtained from the tongue $(O)$ where a $1.3-\mathrm{cm}^{2}$ contactor was used. with a large contactor $\left(1.3 \mathrm{~cm}^{2}\right)$ from the dorsal surface of the tongue, an area of the body that is devoid of Pacinian corpuscles. The $.005 \mathrm{~cm}^{2}$ contactor stimulating the fingerpad, which is richly endowed with Pacinian corpuscles, produces approximately the same thresholds as those measured over the thenar eminence with a contactor 260 times larger $\left(1.3 \mathrm{~cm}^{2}\right)$.

The findings suggest that the distal fingerpad is a body region so densely innervated by Pacinian corpuscles that it is difficult to avoid activating them by using extremely small contactors, but it is difficult or impossible to activate by a low-frequency signal. The results indicate also that threshold responses to vibration obtained at the fingerpad are dominated by the Pacinian corpuscle system for all practical contactor sizes, but not for all frequencies. At low frequencies another receptor system appears to determine the response at threshold intensities regardless of contactor size.

\section{REFERENCES}

HILL, J. W. The perception of multiple tactile stimuli. Technical Report No.4823-1, Stanford Elect. Laboratories, Stanford, California, 1967.

MERZENICK, M, M., \& HARRINGTON, T. The sense of flutter-vibration evoked by stimulation of the hairy skin of primates. Experimental Brain Research, 1969, 9, 236-260.

VERRILLO, R. T. The effect of contactor area on the vibrotactile threshold. Journal of the Acoustical Society of America, 1963, 35, 1962-1966.

VERRILLO, R. T. Effect of spatial parameters on the vibrotactile threshold. Journal of Experimental Psychology, 1966a, 71,570-575.

VERRILLO, R. T. Specificity of a cutaneous receptor. Perception \& Psychophysics, 1966b. $1,149-153$.

VERRILLO, R. T. A duplex mechanism of mechanoreception. In D. R. Kenshalo (Ed.), The skin senses. Springtield: C. C. Thomas, 1968.

WINKELMANN, R. K. Nerve endings in normal and pathological skin. Springfield: C. C. Thomas, 1960.

(Accepted for publication October 1,1970.) 